\title{
COMPREHENSIVE MONETARY EASING IN THE EUROZONE: LESSONS LEARNT FROM JAPAN
}

\author{
LEEF H. DIERKS*
}

Fecha de recepción: 27 de abril de 2020

Fecha de aceptación: 8 de septiembre de 2020

\section{I \\ INTRODUCTION}

The European Central Bank's (ECB) unconventional monetary policy has so far failed to deliver the much-anticipated results. In October 2019, the euro area's (EA-19) HICP-inflation fell to a threeyear low of just $0.7 \%$ year-over-year $(y / y)$, thus being far below the ECB's goal of "below, but close to $2.00 \%$ over the medium term". By November 2019, HICP-inflation had recovered to a modest $1.0 \%$ (y/y) with seasonally-adjusted Eurozone GDP growing at a disappointing 1.2\% (y/y) in Q3 2019 compared with the same quarter of the previous year (Eurostat, 2019). Inevitably, these developments raise the question to what extent the ECB might eventually consider extending its Quantitative Easing $(\mathrm{QE})$ program, i.e. its $€ 2.6 \mathrm{tn}$ asset purchase programs (APP) beyond the ongoing €20bn-permonth purchase of fixed income securities. Any further easing could, for example, foresee an enhancement of the securities purchased to inter alia include shares of stock.

In contrast to widely held beliefs, this by no means were an entirely unprecedented phenomenon, but corresponded to measures

* Prof. Dr. Leef H. Dierks, Professor for Finance and International Capital Markets, Department of Economics, Lübeck University of Applied Sciences, Germany. E-Mail: leef.dierks@th-luebeck.de. The author wishes to express his gratitude to the two anonymous reviewers who provided valuable feedback. 
(so-called comprehensive monetary easing, CME) adopted by the Bank of Japan (BoJ) as early as 2010 (Bank of Japan, 2010a). Notwithstanding the BoJ's CME, however, HICP-inflation in Japan fell to $0.0 \%$ (y/y) in December 2019, the latest date for which data were available, which caused annual HICP-inflation for the full year to drop to only $0.8 \%$ (y/y).

Based on the experiences gained in Japan, and notwithstanding a potential revision of the ECB's inflation target to a $1.5 \%$ to $2.5 \%$ range, this contribution will analyse the extent to which an expansion of the ECB's set of hitherto employed unconventional monetary policies through CME could sustainably stimulate economic growth - and inflation - in the euro area. Preliminary results suggest a rather muted impact.

II THE BANK OF JAPAN'S QUANTITATIVE AND QUALITATIVE MONETARY EASING

\section{Technicalities of the BoJ's Comprehensive Monetary Easing}

Preceded by a long phase of low inflation paired with weak economic growth (fig. 1), which previously adopted unconventional measures such as Quantitative Monetary Easing failed to sustainably alter, the BoJ resorted to buying Exchange Traded Funds (ETFs) in December 2010 as part of its newly adopted CME (Bank of Japan, 2010a). The purchase of ETFs, i.e. passive tracker instruments, which typically bundle all stocks included in an index (e.g. such as the Tokyo Stock Price Index (TOPIX) or the Nikkei-225), ceteris paribus leads to less market distortions than direct purchases of shares of stock (Bank of Japan, 2010a).

$\mathrm{QE}$ is generally understood to be an unconventional monetary policy in which a central bank purchases government (or other) securities from the secondary market in an attempt to increase money supply and to stimulate lending and investment. In the euro area, primary market purchases are explicitly forbidden 
FIGURE 1: CPI-INFLATION AND GDP GROWTH IN JAPAN, 2000-2019 (Y/Y VARIATION IN \%)

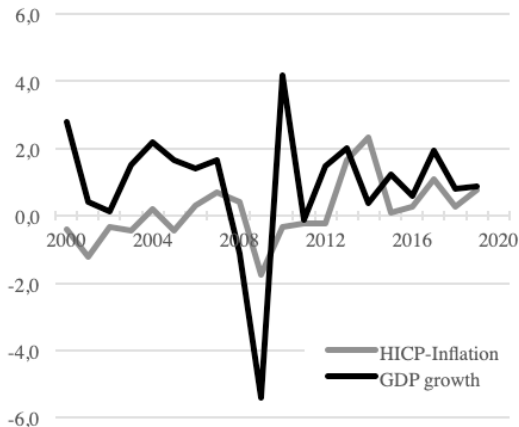

Source: Bank of Japan, 2019.
FIGURE 2: ASSETS HELD BY THE

BOJ WITHIN ITS APP

(2010 - 2020 IN $¥ 100$ TN)

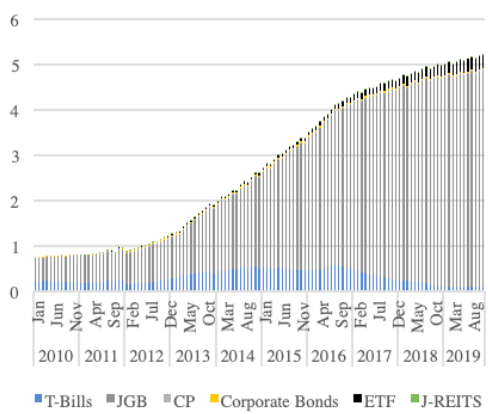

Source: Bank of Japan, 2019.

under Article 123 (1) TFEU, with the ECB's APP thus complying with the prohibition of monetary financing. Qualitative Easing, in contrast, refers to the acceptance of securities with a potentially lower credit rating than those which were previously eligible for purchases within the APP.

Within the scope of its unconventional monetary policy, the BoJ's ETF purchases were initially intended to be an only temporary measure until the end of 2011. The respective volume was limited to $¥ 450 \mathrm{bn}$. With the Japanese consumer price index (CPI) still declining and the Tohoku earthquake adversely affecting economic growth, however, the BoJ decided to considerably increase its APP's overall volume after only four months; doubling it to $¥ 10$ tn from the originally envisaged $¥ 5$ tn (Bank of Japan, 2011a and 2011b). ETF purchases were extended until June 2011 and their volume was doubled to $¥ 900 \mathrm{bn}$. In August 2011, purchases were extended until the end of 2012 and the total volume was further raised to $¥ 1.4 \mathrm{tn}$. As CPI-inflation did not react as intended, the BoJ further increased the limits of its asset purchases throughout the APP's first year. Once the BoJ formally adopted its Quantitative and Qualitative Monetary Easing (QQE) in April 2013, annual ETF 
purchases were set at $¥ 1.0$ tn and time limits were abolished. Shortly after, in October 2014, annual purchases were raised to $¥ 3.0$ tn; now including ETFs that represent the JPX-Nikkei 400 . Since September 2016, annual purchases have totalled $¥ 6.0$ tn (Bank of Japan, 2019).

With c. $¥ 520$ tn as per November 2019 (fig. 2), assets held within the BoJ's QE program almost equal Japan's nominal GDP, which stood at c. $¥ 547 \mathrm{tn}$ in 2018 , the latest date for which data were available (Japan Macro Advisor, 2019). At approximately one, the Japanese assets/GDP ratio thus is four times higher than the respective ratio for the euro area.

By the end of 2019, the BoJ had bought shares in Japanese companies worth c. $¥ 28.1 \mathrm{tn}$. This corresponds to c. $80 \%$ of the outstanding volume (Bank of Japan, 2019). The BoJ has meanwhile become one of the top-10 shareholders in $50 \%$ of all Tokyo-listed companies as a result of it ETF purchases, which raises questions concerning the efficiency of stock market pricing, corporate governance, and a possible exit from this strategy.

Compared to the volume of its government bond (JGB) purchases, the amount of ETFs bought on behalf of the BoJ remains modest. Nevertheless, it should be considered that ETFs do not have a term-to-maturity and generally feature a higher risk attributed to the price volatility. Further, it needs to be assessed how a central bank ought to deal with losses caused by an exit from such monetary policy measure in the event of a pronounced bear market (or crash) on the stock market as any such development would inevitably trigger losses.

Technically, the BoJ limited the maximum amount held of single financial instruments (Bank of Japan, 2010a). In the case of ETFs, the BoJ would conduct purchases in a manner in which the maximum amount purchased would align proportionately with the ETF's total market value. The BoJ did not conduct purchases directly but rather through a trust bank, which acted as a trustee assigned to conduct the purchases within the framework provided by the central bank. The price was set as the respective trading day's volume-weighted average (Bank of Japan, 2010b). The BoJ further described scenarios in which ETFs, among others, could be disposed of, e.g. in case the BoJ's rules no longer are fully complied 
with. Generally, the BoJ aims at "selling assets in a manner minimizing losses and with no distorting effect on the market" (Bank of Japan, 2010b).

\section{Comprehensive Monetary Easing and CPI-inflation}

Despite the BoJ's efforts, neither standard unconventional monetary policy measures nor the more recently adopted ETF purchases succeeded in markedly stimulating Japanese CPI-inflation (Mivao and Okimoto, 2017). A regression analysis indicates that, with a coefficient of determination $\left(\mathrm{R}^{2}\right)$ of only 0.098 , the increase in the broad monetary aggregate M3 in between October 2010 and December 2019 has not had a meaningful impact on Japanese CPI-inflation (fig. 3). Considering the BoJ's asset purchase program, i.e. its ETF purchases, among others, another regression indicates that, with a coefficient of determination $\left(R^{2}\right)$ of only 0.004 , M3 growth in between January 2011 and December 2019, i.e. the period during which purchases have so far been conducted, has not had any impact on the Nikkei-225 (fig. 4).

FIGURE 3: BOJ M3 GROWTH AND

ANNUAL CPI-INFLATION (X-AXIS) IN JAPAN (2010 - 2019)

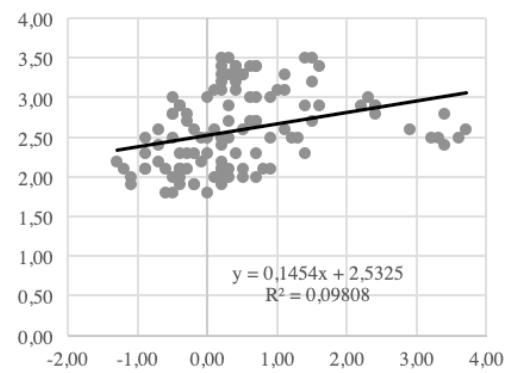

Note: M3 change and CPI-inflation in between October 2010 and December 2019 expressed in $\mathrm{y} / \mathrm{y}$ variation in $\%$. Source: Bank of Japan, 2019.
Figure 4: BOJ M3 AND NIKKEI-225 GROWTH (X-AXIS)

IN JAPAN (2011 - 2019)

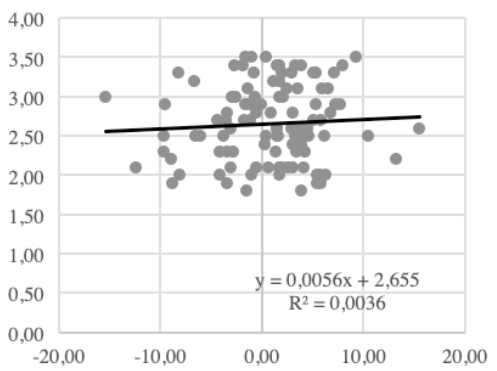

Note: M3 and Nikkei-225 change in between January 2011 and December 2019 expressed in $\mathrm{y} / \mathrm{y}$ variation in $\%$. Source: Bank of Japan, 2019. 
To date, CPI-inflation in Japan has remained well below the BoJ's 2.0\% target. Nonetheless, the BoJ's CME has spurred a stabilisation in long-term (five year) inflation expectations at $1.1 \%$, prompting a typically positive effect on real output (Okimoto, 2019). Further, ETF purchases have had a positive and lasting effect on individual stocks, which has contributed to the rise in inflation expectations. As of late, however, the effectiveness of the BoJ's ETF purchases has considerably weakened. While at the beginning of the CME, the Nikkei-225 still increased by $0.055 \%$ per every $¥ 10$ bn spent, the impact later fell to a modest $0.020 \%$ per every $¥ 10$ bn spent. Since its inception, the cumulative impact of the BoJ's Nikkei-225's ETF purchases has totalled as much as $20 \%$; unintentionally benefitting investors which had, in due course, established long positions in Japanese equity. Naturally, this development raises concerns about potentially unintended consequences of monetary policy (Dierks, 2017) - such as the redistribution of income and wealth.

III

COMPREHENSIVE MONETARY EASING IN THE EURO AREA

\section{1. (In-)Efficiency of Conventional Transmission Mechanism}

A central bank's transmission mechanism refers to “(...) the process through which monetary policy decisions affect the economy in general and the price level in particular. The transmission mechanism is characterised by long, variable and uncertain time lags. Thus it is difficult to predict the precise effect of monetary policy actions on the economy and price level" (European Central Bank, 2020a).

Adopting unconventional monetary policies thus is little but the admission that conventional transmission mechanisms no longer deliver the desired results. In an attempt to fuel economic growth, i.e. to (at least partially) offset the fallout from the financial market crisis and to stimulate inflation, several central banks 
hence resorted to highly accommodative monetary policies and, in several instances, to an outright $\mathrm{QE}$.

\section{A Cautionary Tale for the Euro Area}

The unconventional measures adopted by the ECB seem to have so far failed to sustainably stimulate HICP-inflation and GDP growth in the euro area. At the time of writing, HICP-inflation stood at a modest $1.0 \% \mathrm{y} / \mathrm{y}$ with seasonally-adjusted euro area GDP growing at a disappointing 1.2\% y/y in Q3 2019 compared with the same quarter of the previous year (Eurostat, 2019) (fig. 5). Nonetheless, the developments outlined in fig. 5 should not conceal the fact that, despite (clearly) missing the ECB's 2.0\% medium term inflation target, euro area inflation expectations remain firmly anchored. The 5yr-5yr inflation forward, i.e. the interest rate that market participants expect for five years in five years stood at $1.7 \%$ at the time of writing (European Central Bank, 2020b).

Both conventional and unconventional monetary policies (forward guidance, QE) adopted so far have failed to perceptibly align EA-19 HICP-inflation with the ECB's target of "below, but close to $2.0 \%$ over the medium term", thus questioning the measures' effectiveness. As illustrated in fig. 6, a regression analysis indicates that, with a coefficient of determination $\left(R^{2}\right)$ of only 0.13 , the increase in the monetary aggregate M3 in between December 2010 and December 2019 does not have a meaningful impact on EA-19 HICP-inflation. Instead, with M3 growth (at least temporarily) featuring a decline in HICP-inflation (fig. 6), the principle of money neutrality as suggested by Fisher's quantity equation ought to be scrutinized.

With the highly expansionary monetary policy failing to leave its mark on EA-19 HICP-inflation (fig. 6), markets remain drained in excess liquidity. This, in turn, ultimately poses a viable threat to financial stability as it could ceteris paribus stimulate asset price bubbles, whose correction is, more often than not, accompanied by deflationary tendencies (Chi-Wei et al., 2018 and European Central Bank, 2011). 
FIGURE 5: EA HICP-INFLATION AND GDP GROWTH, 2010-2019

(Y/Y VARIATION IN \%)

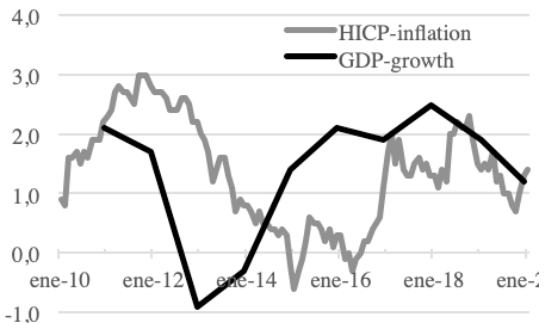

Source: Eurostat, 2020.

FIGURE 7: EURO STOXX 50, 2010-2020 (IN POINTS)

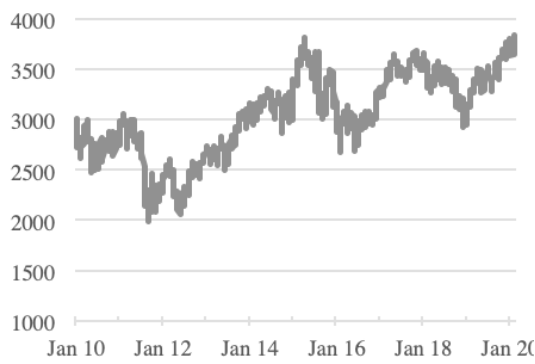

Source: Deutsche Bundesbank, 2020.
FIGURE 6: EURO AREA ANNUAL M3 GROWTH AND Y/Y HICPINFLATION (X-AXIS), 2010-2020

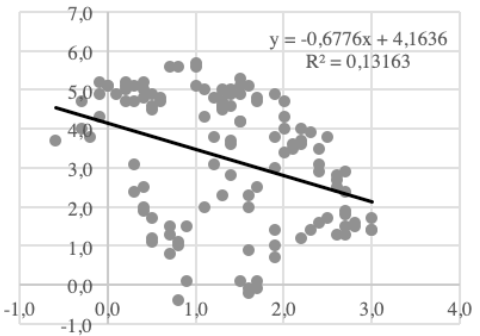

Source: Author's own based on ECB, 2020c.

FIGURE 8: DAX-30, 2000-2020 (IN POINTS)

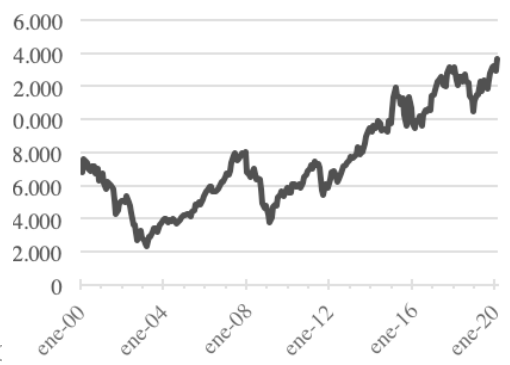

Source: Deutsche Bundesbank, 2020.

Later adopting countermeasures to address any such recessionary and/or deflationary pressures might prove to be challenging as a further easing of a zero interest rate policy (ZIRP) paired with QE is unfeasible (European Central Bank, 2011). Even when inter alia considering factors such as the (six to eight month) time lag of monetary policy, conventional and unconventional transmission mechanisms appear to have reached their limits. The euro area, it seems, is caught in a liquidity trap.

To the extent that assets acquired within the scope of the ECB's APP have meanwhile amounted to as much as €2.6tn, asset price 
inflation appears to have gained considerable momentum. In the euro area, this becomes particularly evident when assessing the development of real estate, property and equity prices with the leading blue chips indicators, EURO STOXX 50 and DAX-30, reaching their all-time high in mid-February 2020 - despite economic headwinds, which can inter alia be attributed to the coronavirus outbreak (fig. 7 and 8).

FIGURE 9: EURO AREA M3 AND GERMAN DAX-30 (X-AXIS), 2010-2019

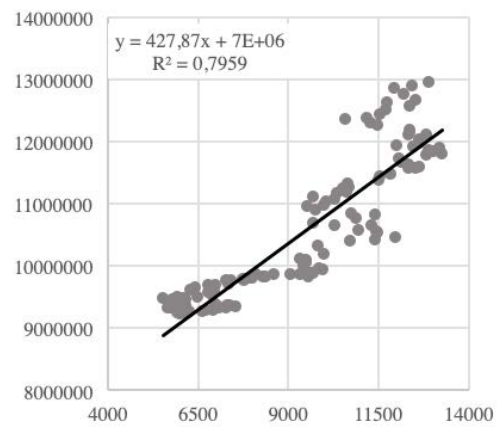

FIGURE 10: EURO AREA M3 AND GERMAN REAL ESTATE INDEX (GREI) (X-AXIS), 2010-2019

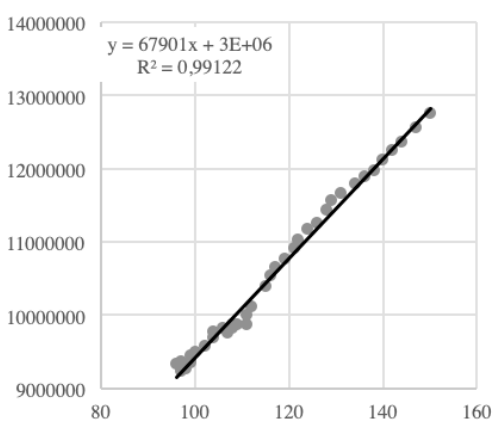

Source: Author's own based on ECB, 2020c. Source: Author's own based on ECB, 2020c.

Fig. 9 features the correlation between euro area M3 and the German DAX-30, with a coefficient of determination $\left(\mathrm{R}^{2}\right)$ of c. 0.80 . As illustrated above, the ECB's QE has, at least partially, contributed to the ongoing bull market. An even higher correlation can be observed when comparing euro area M3 to the German real estate index (GREI) in between January 2010 and July 2019, the latest date for which data were available. Fig. 10 features an almost linear relationship between M3 and GREI with $\mathrm{R}^{2}$ standing at a very high 0.99. Whereas EA-19 HICP inflation has (so far) not reacted materially to the increase in $\mathrm{M} 3$, prices for both financial assets and real estate did. As this development does not appear to be fundamentals-driven, though, but instead started upon the ECB's announcement of its APP, i.e. before any purchases were actually conducted 
(signalling effect), it might pose a mounting risk to financial stability (Valiante, 2017).

Even if correlation is not to be confused with causality, it seems that the additional liquidity provided by the ECB has affected asset prices in a considerable manner; benefitting those who already possessed appropriate assets. However, since wages and salaries developed disproportionately compared to this development, a higher proportion of the net disposable income is required to acquire corresponding positions these days, which indicates a continuously deteriorating affordability.

Considering the similarities between CPI-inflation in Japan and the euro area (Dierks, 2015), stock (ETF) purchases as conducted by the BoJ could, at first glance, obviously complement the ECB's current monetary policy strategy. As supported by other empirical studies (Chi-Wei et al., 2018), the absence of any meaningful correlation between stock purchases and the development of the Nikkei 225 (fig. 4) indicates that the BoJ's intervention in the stock market (so far) has not contributed to the risk of a speculative bubble. Nonetheless, ETF purchases increase the aggregate demand for stocks, which ceteris paribus leads to a rise in stock prices, in turn enhancing inflation through the wealth channel (Huston and Spencer, 2016).

The EA-19's currently modest annual HICP-inflation should not belie the fact that a steadily mounting asset price inflation poses a threat to financial stability. Attributed to the ongoing hunt-foryield, speculative bubbles, which ex ante cannot be identified, could gather further momentum. Any correction, however, left asset markets in a vulnerable state - as the portfolio rebalancing effect forced institutional investors into riskier assets; a potentially vicious circle the ECB needs to carefully consider when ending its monetary stimulus.

IV

\section{CONCLUSION}

As the BoJ was first to adopt several unconventional monetary policies, among them CME, its course of action can partially be 
considered a blueprint for other central banks. Yet, even as resorting to forward guidance, ZIRP, negative interest rates, and Quantitative as well as Qualitative Easing failed to meaningfully lift inflation off its zero bound, it seems that for the most part, such measures have not had the desired outcome. Evidence from Japan suggests that it remains stuck in a liquidity trap; a scenario, which no longer is inconceivable for the euro area, too.

Lessons learnt from the BoJ's CME therefore ought to be a cautionary tale for the euro zone. Whereas little seems to be gained in terms of stimulating HICP-inflation by means of CME, a lot is to be lost; particularly considering its many unintended consequences. Mounting risks to financial stability in the shape of speculative bubbles and the distinct redistribution of income and wealth could further delay the normalization of the ECB's monetary policy.

Above findings do not suggest that, considering its commitment to do "whatever it takes to preserve the euro", the ECB could not adopt additional unconventional measures in case euro area HICP-inflation fails to recover towards its target of "below, but close to $2.0 \%$ over the medium term". Following the ongoing revision of its monetary policy, however, the ECB could of course decide to adjust its inflation target. A range of $1.5 \%$ to $2.5 \%$ as currently discussed (Financial Times, 2019), for example, considerably lowered the pressure to further pursue $\mathrm{QE}$ - and could, to such an extent, pave the way for the normalisation of the ECB's monetary policy.

\section{BIBLIOGRAPHY}

Bank of Japan (2010a), Establishment of "Principal Terms and Conditions for Purchases of ETFs and J-REITs Conducted through the Asset Purchase Program", https://www.boj.or.jp/en/ announcements/release_2010/mok1011b.pdf

Bank of Japan (2010b), Statement on Monetary Policy, https://www. boj.or.jp/en/announcements/release_2010/k101105.pdf

Bank of Japan (2011a), Amendment to "Principal Terms and Conditions for the Asset Purchase Program", https://www.boj.or.jp/ en/announcements/release_2011/rel110314i.pdf. 
Bank of Japan (2011b), Enhancement of Monetary Easing, https:// www.boj.or.jp/en/announcements/release_2011/k110314a.pdf.

Bank of Japan (2019a), Asset Holdings of the BoJ under the APP, http://www.stat-search.boj.or.jp/ssi/html/nme_ R031.5246.20191213025816.02.csv.

Chi-Wei, S. U.; Kai-Hua, Wang; Ran, T. A.O.; Hsu-Ling, Chang (2018): Too Much or Less? Money Supply in Japan, in: Economic Computation and Economic Cybernetic Studies and Research, 52 (2018), no. 3/2018, p. 21-38.

Deutsche Bundesbank (2020), DAX-30, https://www.bundesbank. de/dynamic/action/de/startseite/suche/statistiken/sucheim-zeitreihen-code/747632/titelsuche-in-der-zeitreihendatenbank?query $=$ dax.

Dierks, L. H. (2015), Droht der Europäischen Währungsunion eine "Japanisierung"? in Wirtschaftswissenschaftliches Studium: WiSt, Vol. 44, 1, p. 30-36.

- (2017), "Playing with Fire: The Unintended Consequences of Monetary Financing", in Procesos de Mercado: Revista Europea de Economía Política, Vol. XIV, no. 2, autumn 2017, p. 247-257.

European Central Bank (2011), Die Geldpolitik der EZB, 3rd ed., Frankfurt am Main.

European Central Bank, 2020a, Transmission mechanism of monetary policy, https://www.ecb.europa.eu/mopo/intro/transmission/html/index.en.html.

European Central Bank, 2020b. ECB survey of professional forecasters (SPF), https://www.ecb.europa.eu/stats/ecb_surveys/survey_of_ professional_forecasters/html/ecb.spf2019q4 909ade9ae4.en. html\#toc2

European Central Bank, 2020c. M3 stock, European Central Bank (2019j): M3 Stock, http://sdw.ecb.europa.eu/quickview. do?SERIES_KEY=117.BSI.M.U2.Y.V.M30.X.1.U2.2300.Z01.E.

Eurostat, 2019. Inflation in the euro area, https:/ec.europa.eu/ eurostat/statistics-explained/index.php/Inflation_in_the_ euro_area.

Financial Times (2019), FT Poll: Christine Lagarde Expected to Change Inflation Target.https://www.ft.com/content/e70324381d14-11ea-9186-7348c2f183af. 
Japan Macro Advisor (2019), Japan Nominal Gross Domestic Product (GDP), https://www.japanmacroadvisors.com/page/category/ economic-indicators/gdp-and-business-activity/nominal-gdp/.

Huston, J.H. and R.W. Spencer (2016), “The Wealth Effects of Quantitative Easing", in: Atlantic Economic Journal, 44 (2016), no. 4, p. 471-486.

Miyao, R. and T. Okimoto (2017), "The Macroeconomic Effects of Japan's Unconventional Monetary Policies", RIETI Discussion Paper, 17-E-065.

Okimoto, T. (2019), “Trend Inflation and Monetary Policy Regimes in Japan", Journal of International Money and Finance 92, p. 137152.

Valiante, D. (2017): “The 'Visible Hand' of the ECB's first quantitative easing", in: International Economics and Economic Policy, 14 (2017), no. 4, p. 60. 